\title{
Two-Phase Ligand Exchanges on CdSe Nanoplatelets
}

\author{
Chenguang Ji and William E. Buhro* \\ Department of Chemistry and Institute of Materials Science and Engineering, Washington \\ University, St. Louis, Missouri 63130-4899. \\ Corresponding Author: buhro@wustl.edu
}

Table of Contents:

\begin{tabular}{ll}
\hline Calculation of ideal ligation stoichiometries & S2
\end{tabular}

Calculation of combustion-based elemental analysis data $\quad$ S3

Figure S1 IR spectra of $\left\{\mathrm{CdSe}[n \text {-octylamine }]_{0.55}\right\}$ NPLs before and after removal of the amine-hemihydrate

Figure S2 Absorption spectra of $\left\{\mathrm{CdSe}[n \text {-octylamine }]_{0.55}\right\}$ NPLs before and after removal of the amine-hemihydrate

Figure S3 XRD patterns of $\mathrm{CdX}_{2}$-ligated CdSe NPLs after two-phase exchange $\quad$ S6

Figure S4 TEM images of $\mathrm{CdX}_{2}$-ligated CdSe NPLs after two-phase exchange $\quad$ S7

Figure S5 Photographs of DMF dispersions of variously ligated CdSe NPLs over time $\quad$ S8

Figure S6 Absorption spectra of $\mathrm{CdX}_{2}$-ligated CdSe NPLs after single-phase exchange $\quad$ S9

Figure S7 Absorption spectra of $\mathrm{CdX}_{2}$-ligated CdSe NPLs after DMF washing $\quad$ S9

Table S1 Compositions of $\mathrm{CdX}_{2}$-Ligated CdSe NPLs prepared by different methods $\quad$ S10

$\begin{array}{lll}\text { Figure S8 XRD patterns of } \mathrm{NH}_{3} \text {-ligated CdSe NPLs } & \text { S11 }\end{array}$

Figure S9 $\quad$ TEM images of $\mathrm{NH}_{3}$-ligated CdSe NPLs $\quad \mathrm{S} 12$

Figure S10 IR spectra of pure $\left[\mathrm{NH}_{4}\right] \mathrm{X}$ salts and [n-octylammonium]Cl salt $\quad \mathrm{S} 13$

Figure S11 Absorption spectra after attempted two-phase exchange with AX salts $\quad$ S14

$\begin{array}{lll}\text { Figure S12 } & \text { IR spectra after attempted two-phase exchange with AX salts } & \text { S14 }\end{array}$

Table S2 Lowest-Energy Absorptions of [ $\left.\mathrm{NH}_{4}\right]$ X-Ligated CdSe NPLs $\quad$ S15

Figure S13 Apparatus for conducting ligand exchange with gaseous $\mathrm{NH}_{3} \quad \mathrm{~S} 16$ 


\section{Calculation of Ideal Ligation Stoichiometries}

The wurtzite CdSe NPLs studied here have a mean length of $21 \pm 3 \mathrm{~nm}$, a mean width of $6 \pm$ $1 \mathrm{~nm}$, and a discrete thickness of $1.8 \mathrm{~nm}$, or 5 monolayers (MLs) of CdSe. The top, bottom, and long-edge facets are nonpolar (Figure 1), which means that they contain equal numbers of $\mathrm{Cd}$ and Se atoms. Two of the 5 MLs lie on the broad top and bottom facets, which means that $40 \%$ of the $\mathrm{Cd}$ and Se atoms in the NPLs are on the top and bottom surfaces.

The ratio of the thickness to the mean width is $1.8 \mathrm{~nm} / 6 \mathrm{~nm}=0.3$. The $\mathrm{Cd}$ and Se atoms lying on the long-edge facets is thus $(0.3)(40 \%)=12 \%$. Thus the total $\mathrm{Cd}$ and Se atoms lying on the top, bottom, and edge facets is $52 \%$. Of these surface $\mathrm{Cd}$ and Se atoms, only half are available for ligation. Thus, the stoichiometry for binding one ligand per ligation-available $\mathrm{Cd}$ or $\mathrm{Se}$ atom is $\left\{\mathrm{CdSe}[\mathrm{L}]_{0.26}\right\}$ or $\left\{\mathrm{CdSe}[\mathrm{Z}]_{0.26}\right\}$. If ligands bind to both the ligation-available $\mathrm{Cd}$ and $\mathrm{Se}$ atoms, the ideal stoichiometry is $\left\{\mathrm{CdSe}[\mathrm{L}]_{0.52}\right\}$.

The ratio of the thickness to the mean length is $1.8 \mathrm{~nm} / 21 \mathrm{~nm}=0.086$. The $\mathrm{Cd}$ and Se atoms lying on the small end facets is thus $(0.086)(40 \%)=3.4 \%$. These facets are polar, likely have different surface chemistry from the nonpolar facets, and are present in such small areas that we may ignore them. 
Calculation of Combustion-Based Elemental Analysis Data.

\begin{tabular}{|c|c|c|c|c|}
\hline CdSe $[n \text {-octylamine }]_{0.550 \pm 0.003}{ }^{a}$ & $\mathrm{C}(\%)$ & $\mathrm{H}(\%)$ & $\mathrm{N}(\%)$ & $\mathrm{X}(\%)$ \\
\hline Calcd & 20.13 & 3.98 & 2.93 & N/A \\
\hline Found & 20.23 & 3.96 & 2.91 & N/A \\
\hline Found & 20.09 & 3.98 & 2.89 & N/A \\
\hline $\mathrm{CdSe}[n \text {-octylamine }]_{0.549 \pm 0.006^{b}}$ & $\mathrm{C}(\%)$ & $\mathrm{H}(\%)$ & $\mathrm{N}(\%)$ & $\mathrm{X}(\%)$ \\
\hline Calcd & 20.11 & 3.98 & 2.93 & N/A \\
\hline Found & 19.99 & 3.93 & 2.78 & N/A \\
\hline Found & 20.24 & 3.94 & 2.82 & N/A \\
\hline $\begin{array}{l}\mathrm{CdSe}\left[\mathrm{NH}_{3}\right]_{0.25}[\mathrm{HCl}]_{0.07}[n- \\
\text { octylamine }]_{0.13}\end{array}$ & $\mathrm{C}(\%)$ & $\mathrm{H}(\%)$ & $\mathrm{N}(\%)$ & $\mathrm{X}(\%)$ \\
\hline Calcd & 5.80 & 1.50 & 2.47 & 1.15 \\
\hline Found & 5.93 & 1.39 & 2.47 & 1.18 \\
\hline $\begin{array}{c}\mathrm{CdSe}\left[\mathrm{Br}^{-}\right]_{0.29}\left[\mathrm{NH}_{4}^{+}\right]_{0.26}[n- \\
\text { octylamine }]_{0.17}\end{array}$ & $\mathrm{C}(\%)$ & $\mathrm{H}(\%)$ & $\mathrm{N}(\%)$ & $\mathrm{X}(\%)$ \\
\hline Calcd & 6.78 & 1.77 & 2.50 & 9.62 \\
\hline $\begin{array}{c}\text { Found } \\
\end{array}$ & 6.84 & 1.62 & 2.52 & 9.61 \\
\hline $\begin{array}{c}\mathrm{CdSe}\left[\mathrm{Cl}^{-}\right]_{0.36}[n \text {-octylammonium }]_{0.32}\left[\mathrm{NH}_{4}{ }^{+}\right]_{0.04}[n- \\
\text { octylamine }]_{0.10}\end{array}$ & $\mathrm{C}(\%)$ & $\mathrm{H}(\%)$ & $\mathrm{N}(\%)$ & $\mathrm{X}(\%)$ \\
\hline Calcd & 15.56 & 3.14 & 2.49 & 4.92 \\
\hline Found & 15.69 & 2.99 & 2.48 & 4.88 \\
\hline $\begin{array}{c}\mathrm{CdSe}\left[\mathrm{NH}_{3}\right]_{0.25 \pm 0.06}[n \text {-octylamine }]_{0.09 \pm} \\
0.02\end{array}$ & $\mathrm{C}(\%)$ & $\mathrm{H}(\%)$ & $\mathrm{N}(\%)$ & $\mathrm{X}(\%)$ \\
\hline Calcd & 4.17 & 1.19 & 2.30 & N/A \\
\hline Found & 3.44 & 1.06 & 2.50 & N/A \\
\hline Found & 4.78 & 1.16 & 2.10 & N/A \\
\hline
\end{tabular}

${ }^{a}$ As-synthesized NPLs (after removal of the amine-hemihydrate impurity).

${ }^{b}$ After back exchange from $\mathrm{NH}_{3}$ ligation with $n$-octylamine.

Example calculation of empirical formula from elemental-analysis data: determining the empirical formula of $\mathrm{CdSe}\left[\mathrm{NH}_{3}\right]_{0.25}[\mathrm{HCl}]_{0.07}[n \text {-octylamine }]_{0.13}$

$\mathrm{M}_{n \text {-octylamine }}=129.24 \mathrm{~g} / \mathrm{mol}$

$\mathrm{M}_{\mathrm{CdSe}}=191.39 \mathrm{~g} / \mathrm{mol}$

$\mathrm{M}_{\mathrm{NH} 3}=17.03 \mathrm{~g} / \mathrm{mol}$

Assume the mass of the sample is $100 \mathrm{~g}$.

$\mathrm{m}_{\mathrm{C}+\mathrm{H}+\mathrm{N}+\mathrm{Cl}}=5.93+1.39+2.47+1.18=10.97 \mathrm{~g}$

$\mathrm{m}_{\mathrm{CdSe}}=100-10.97=89.03 \mathrm{~g}$

number of moles of $\mathrm{CdSe}=89.03 / 191.39=0.4652$

number of moles of $\mathrm{Cl}=1.18 / 35.45=0.033$

number of moles of $n$-octylamine $=5.93 /(12.01 \times 8)=0.062$ 
total number of moles of $\mathrm{N}=2.47 / 14.00=0.176$

number of mole of $\mathrm{N}$ from $n$-octylamine $=0.062$

number of mole of $\mathrm{NH}_{3}=0.176-0.062=0.114$

Thus the ratio of $\mathrm{Cl}, n$-octylamine and $\mathrm{NH}_{3}$ to $\mathrm{CdSe}$ is $0.07,0.13$ and 0.25 , respectively.

So the empirical formula is $\mathrm{CdSe}\left[\mathrm{NH}_{3}\right]_{0.25}[\mathrm{HCl}]_{0.07}[n \text {-octylamine }]_{0.13}$ 


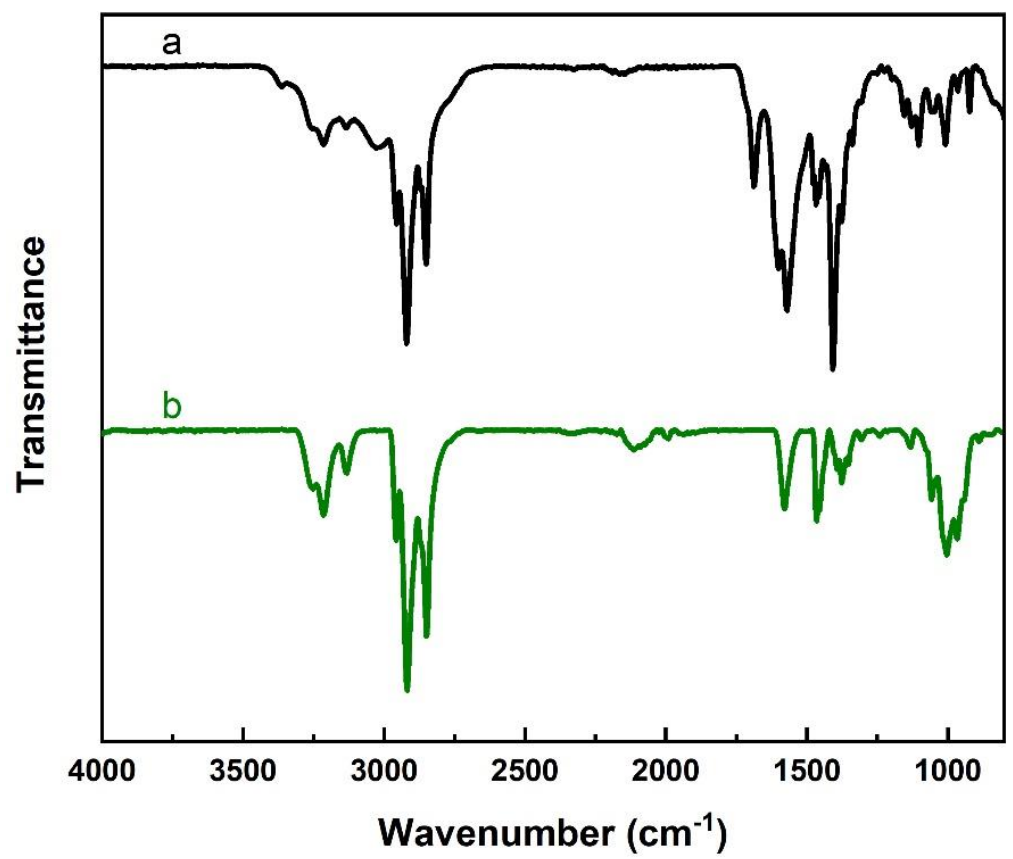

Figure S1. IR spectra of (a) as-synthesized CdSe NPLs (with amine-hemihydrate impurity); (b) $n$-octylamine-ligated $\left\{\mathrm{CdSe}[n \text {-octylamine }]_{0.55}\right\}$ NPLs (after removal of the amine-hemihydrate impurity).

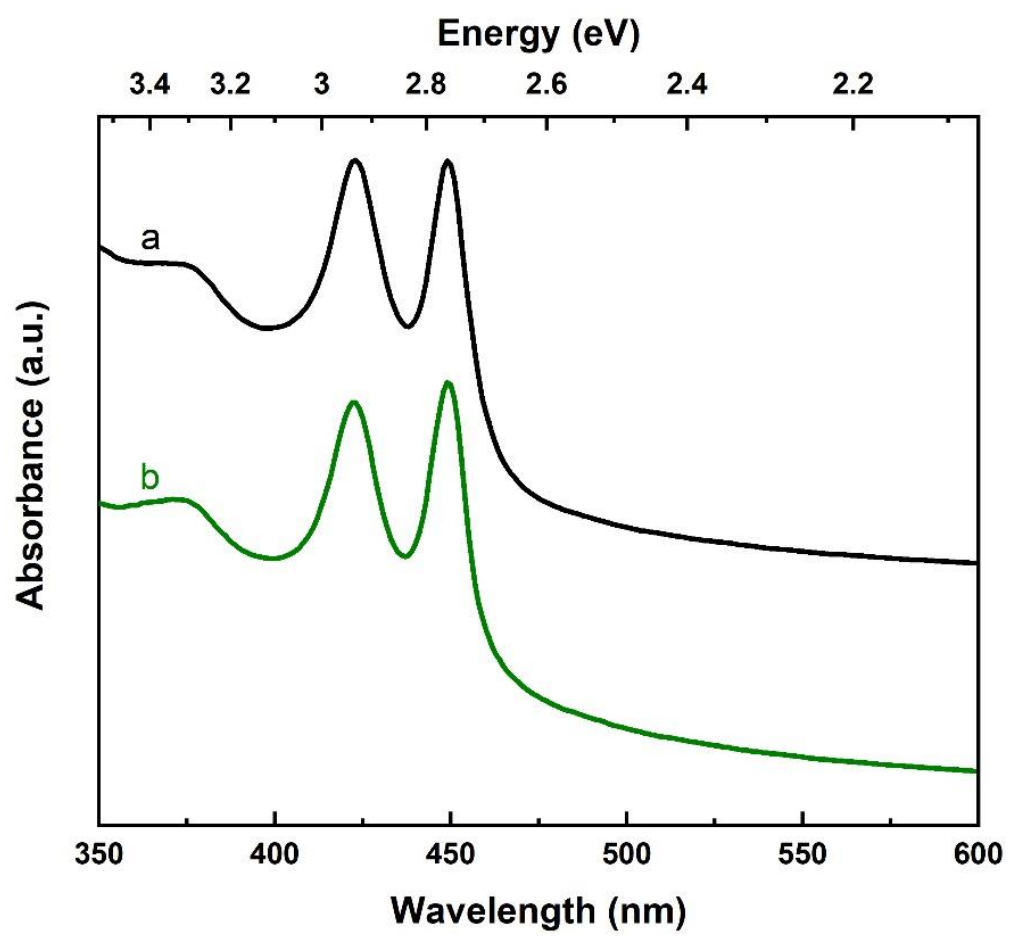

Figure S2. Absorption spectra of (a) as-synthesized CdSe NPLs (with amine-hemihydrate impurity); (b) $n$-octylamine-ligated $\left\{\mathrm{CdSe}[n \text {-octylamine }]_{0.55}\right\}$ NPLs (after removal of the aminehemihydrate impurity). 


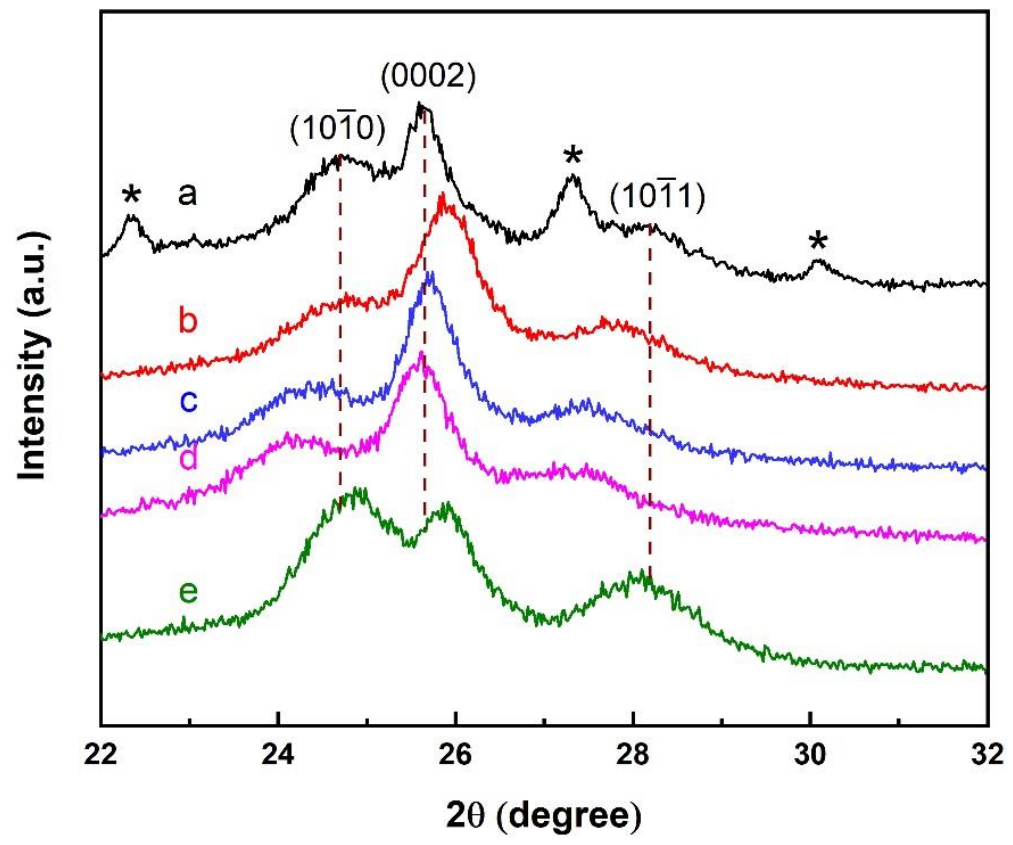

Figure S3. XRD patterns of (a) as-synthesized CdSe NPLs and $\mathrm{CdX}_{2}$-ligated NPLs after ligand exchange: (b) $\mathrm{CdCl}_{2}$; (c) $\mathrm{CdBr}_{2}$; (d) $\mathrm{CdI}_{2}$. (e) $\left\{\mathrm{CdSe}[n \text {-octylamine }]_{0.55}\right\}$ NPLs after back exchange from $\mathrm{CdCl}_{2}$ ligation with $n$-octylamine. Reflections corresponding to the di- $n$ octylamine $\cdot 0.5 \mathrm{H}_{2} \mathrm{O}$ impurity are identified with asterisks. The vertical dashed lines are to guide the eye. The relative shifting of the reflections in the patterns is due to the differing strain state induced by the various ligands. The difference in the peak height of the 0002 reflection in (a) and (e) is due to NPL bundling in the back-exchanged $n$-octylamine-ligated NPLs (e). 

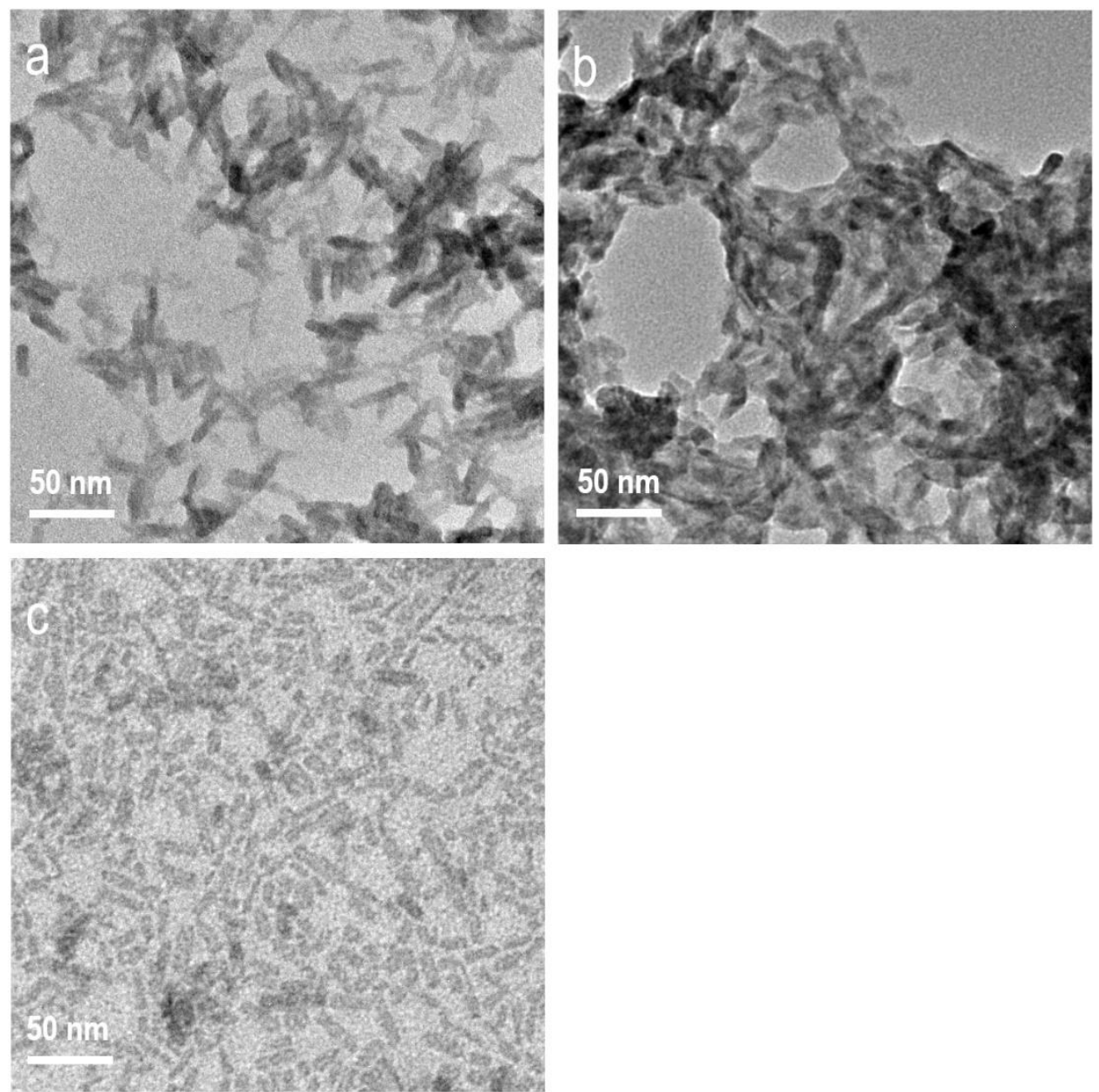

Figure S4. TEM images of $\mathrm{CdX}_{2}$ ligated NPLs obtained by two-phase ligand exchange : (a) $\mathrm{CdCl}_{2}$; (b) $\mathrm{CdBr}_{2}$; (c) $\mathrm{CdI}_{2}$. 


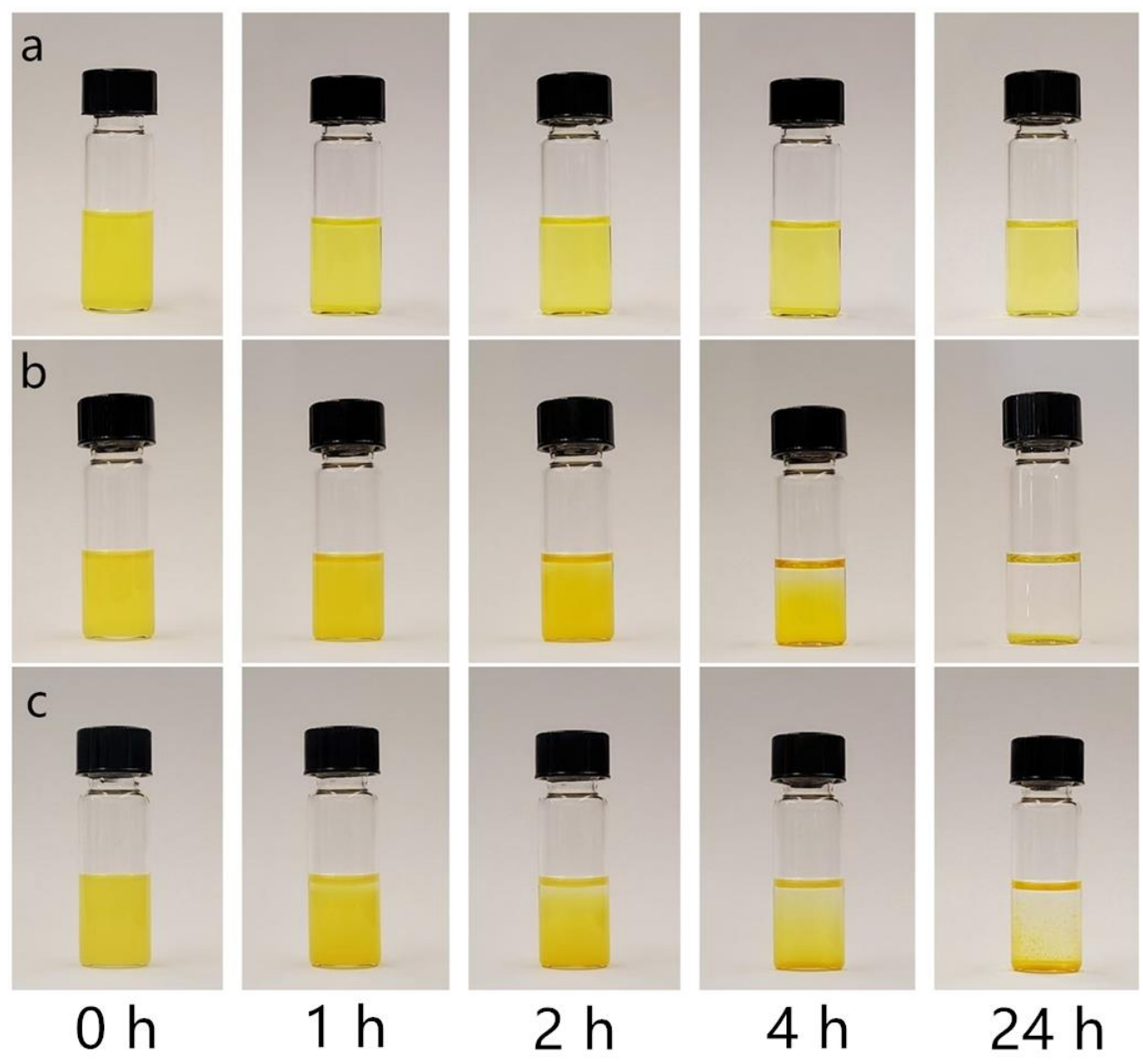

Figure S5. Photographs of DMF dispersions of variously ligated CdSe NPLs over time to assess dispersion stability. (a) $\mathrm{CdCl}_{2}$-ligated NPLs; precipitation began in $2-4 \mathrm{~h}$. (b) $\mathrm{NH}_{3}$-ligated NPLs prepared from $\left[\mathrm{NH}_{4}\right] \mathrm{Cl}$; precipitation began in $1-2 \mathrm{~h}$. (c) $\mathrm{NH}_{3}$-ligated NPLs prepared from $\mathrm{NH}_{3}(\mathrm{~g})$; precipitation began in $1-2 \mathrm{~h}$. 


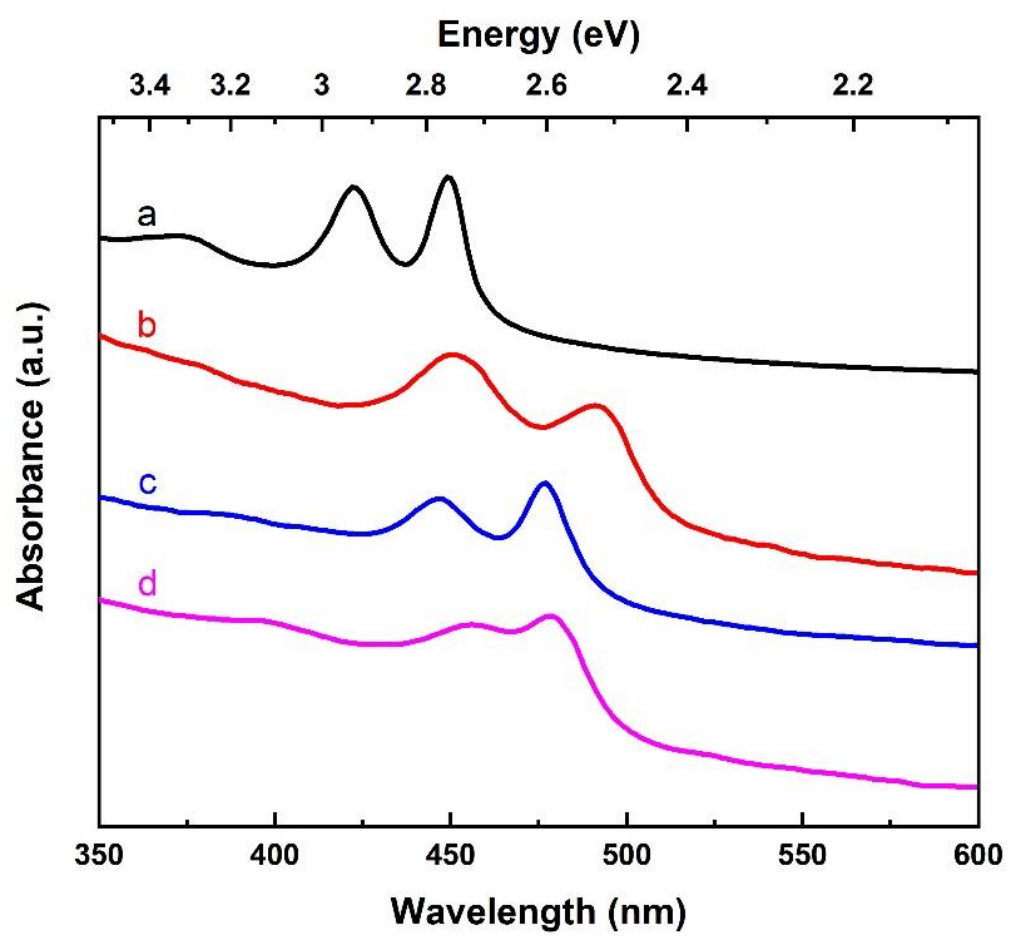

Figure S6. Absorption spectra of (a) as-synthesized CdSe NPLs and $\mathrm{CdX}_{2}$-ligated NPLs after single-phase ligand exchange in toluene/methanol: (b) $\mathrm{CdCl}_{2}$; (c) $\mathrm{CdBr}_{2}$; (d) $\mathrm{CdI}_{2}$.

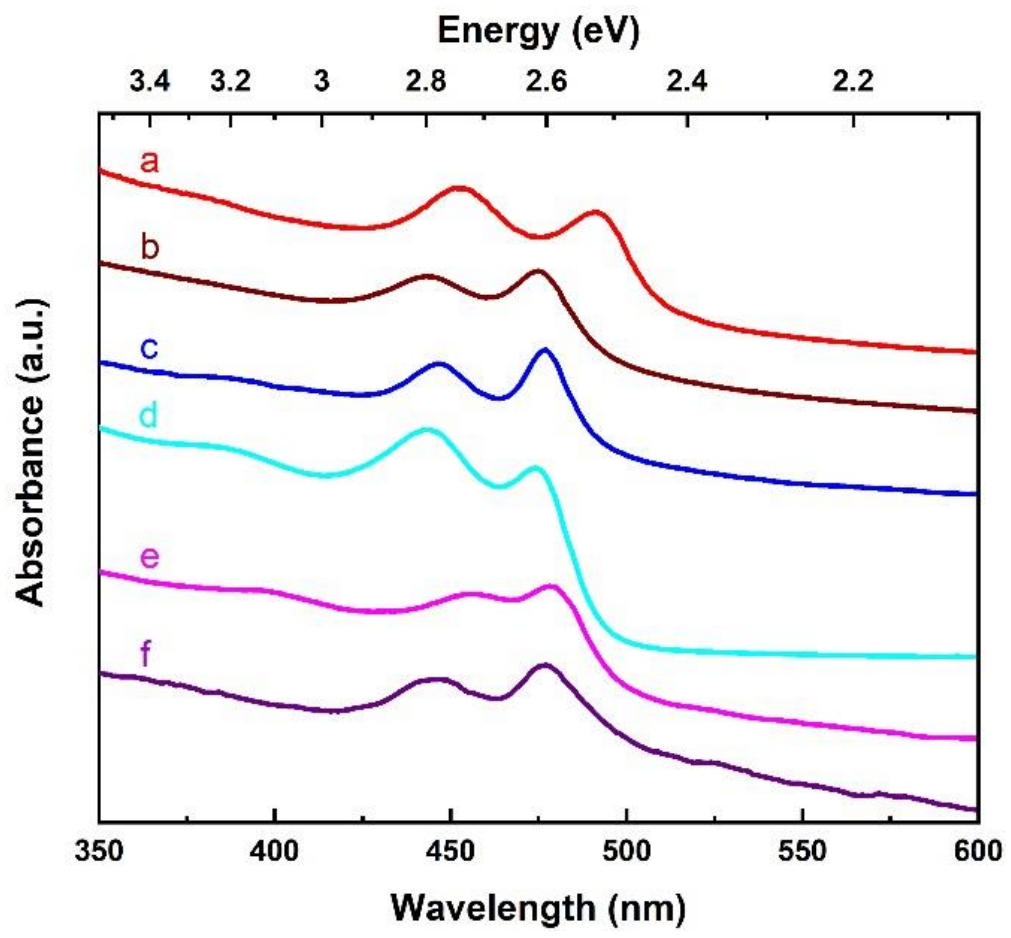

Figure S7. Absorption spectra of $\mathrm{CdX}_{2}$-ligated NPLs after single-phase ligand exchange in toluene/methanol: (a) $\mathrm{CdCl}_{2}$; (c) $\mathrm{CdBr}_{2}$; (e) $\mathrm{CdI}_{2}$; and the corresponding spectra of the $\mathrm{CdX}_{2}$ ligated NPLs after a single wash with DMF: (b) $\mathrm{CdCl}_{2}$; (d) $\mathrm{CdBr}_{2}$; (f) $\mathrm{CdI}_{2}$. 
Table S1. Compositions of $\mathrm{CdX}_{2}$-Ligated CdSe NPLs Prepared by Different Methods Determined from Cd/Se Ratios. ${ }^{a}$

\begin{tabular}{cccc}
\hline NPL specimen & Toluene/methanol & $\begin{array}{c}\text { Cd/Se ratio } \\
\text { After DMF wash }\end{array}$ & DMF/hexane \\
\hline$\left\{\mathrm{CdSe}\left[\mathrm{CdCl}_{2}\right]_{x}\right\}$ & $2.3 \pm 0.7$ & $1.26 \pm 0.06$ & $1.27 \pm 0.06$ \\
$\left\{\mathrm{CdSe}\left[\mathrm{CdBr}_{2}\right]_{y}\right\}$ & $1.6 \pm 0.2$ & $1.30 \pm 0.08$ & $1.24 \pm 0.09$ \\
$\left\{\mathrm{CdSe}\left[\mathrm{CdI}_{2}\right]_{z}\right\}$ & $1.5 \pm 0.2$ & $1.24 \pm 0.09$ & $1.26 \pm 0.05$ \\
\hline
\end{tabular}

${ }^{a}$ The values in the table are $\mathrm{Cd} / \mathrm{Se}$ ratios measured by EDS. The ratios under "After DMF wash" were for samples originally prepared in toluene/methanol and subsequently washed by DMF (see the main text). 


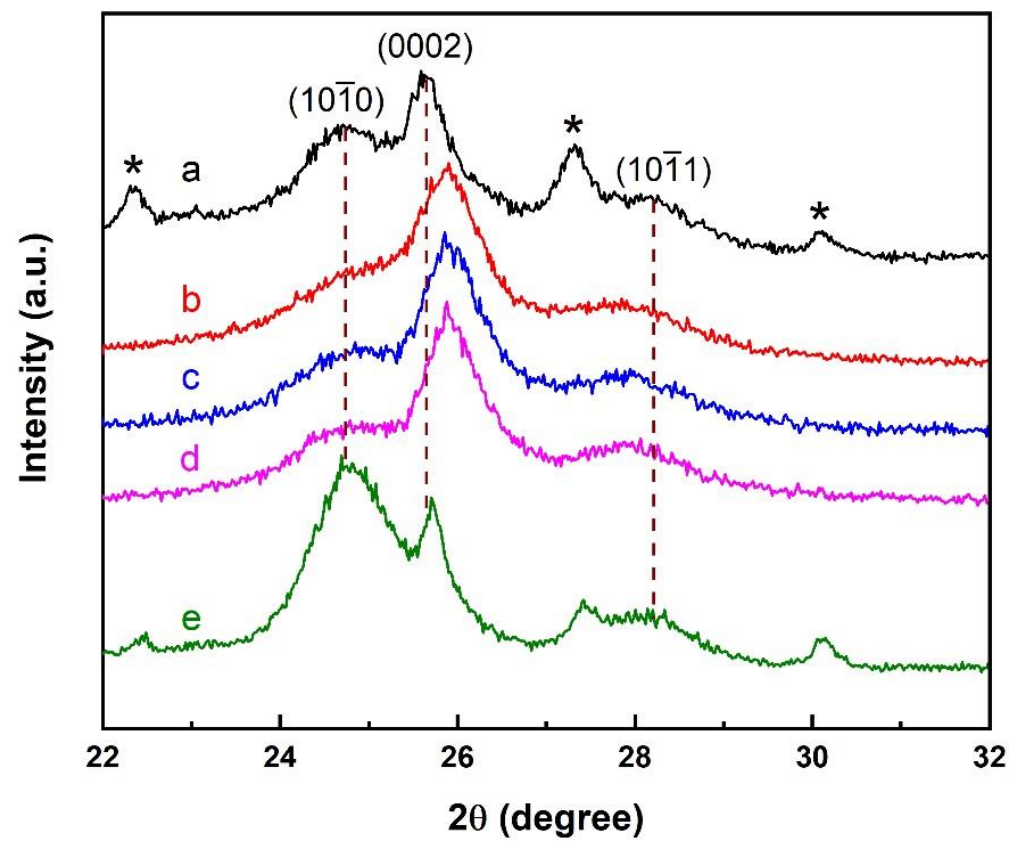

Figure S8. XRD patterns of (a) as-synthesized CdSe NPLs and $\mathrm{NH}_{3}$-ligated CdSe NPLs obtained by two-phase ligand exchange, from (b) $\mathrm{NH}_{4} \mathrm{Cl}$; (c) $\mathrm{NH}_{4} \mathrm{Br}$; (d) $\mathrm{NH}_{4} \mathrm{I}$. (e) $\{\mathrm{CdSe}[n$ octylamine $]_{0.55}$ N NLs after back exchange from $\mathrm{NH}_{3}$ ligation with $n$-octylamine. Reflections corresponding to the di- $n$-octylamine $\cdot 0.5 \mathrm{H}_{2} \mathrm{O}$ impurity are identified with asterisks. The vertical dashed lines are to guide the eye. The relative shifting of the reflections in the patterns is due to the differing strain state induced by the various ligands. The difference in the peak height of the 0002 reflection in (a) and (e) is due to NPL bundling in the back-exchanged $n$-octylamine-ligated NPLs (e). 

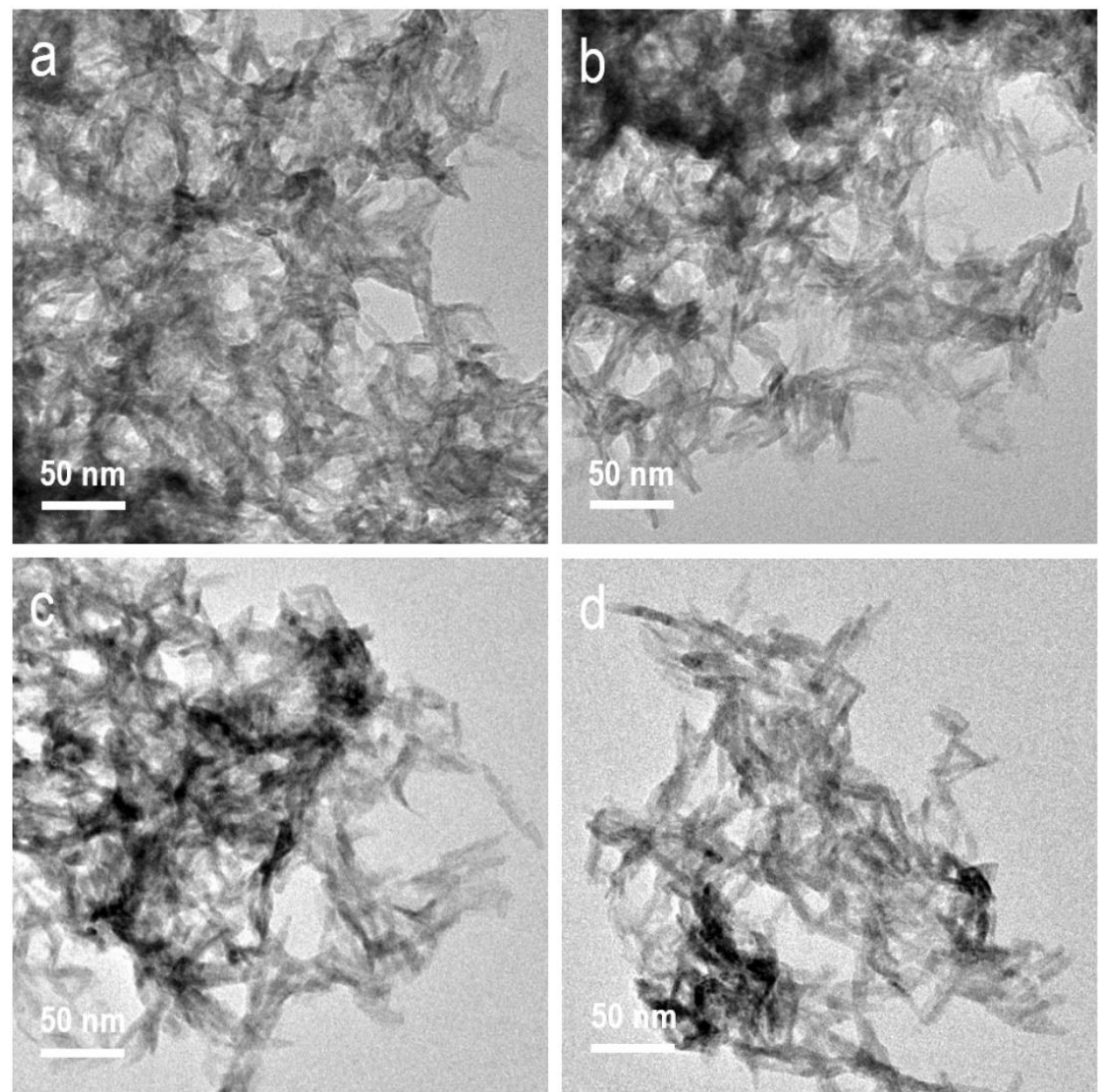

Figure S9. TEM images of $\mathrm{NH}_{3}$-ligated CdSe NPLs obtained by two-phase ligand exchange, from (a) $\mathrm{NH}_{4} \mathrm{Cl}$; (b) $\mathrm{NH}_{4} \mathrm{Br}$; (c) $\mathrm{NH}_{4} \mathrm{I}$; and (d) $\mathrm{NH}_{3}$ (g). 


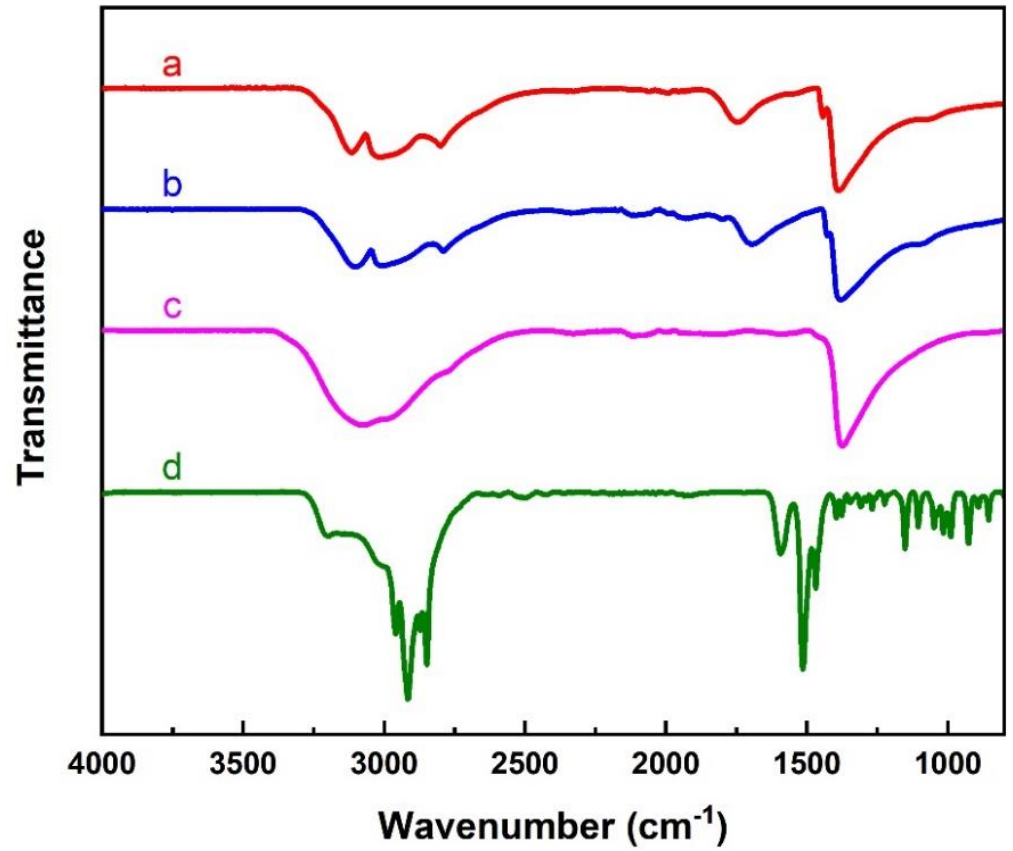

Figure S10. IR spectra of pure $\left[\mathrm{NH}_{4}\right] \mathrm{X}$ salts: (a) $\left[\mathrm{NH}_{4}\right] \mathrm{Cl}$; (b) $\left[\mathrm{NH}_{4}\right] \mathrm{Br}$; and (c) $\left[\mathrm{NH}_{4}\right] \mathrm{I}$. (d) The IR spectrum of independently prepared [n-octylammonium]Cl salt. 


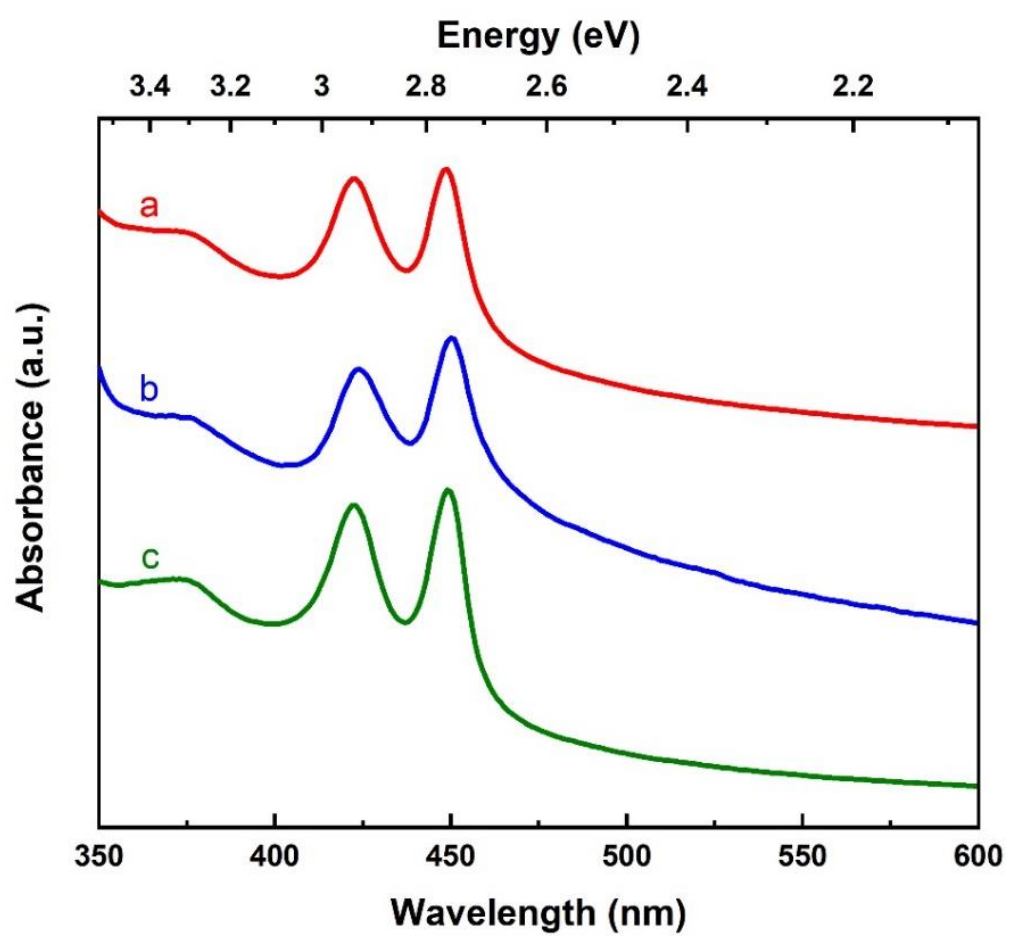

Figure S11. Absorption spectra after attempted two-phase ligand exchange with (a) $\mathrm{NaCl}$, and (b) $\mathrm{CsBr}$, and (c) after addition of excess $n$-octylamine to sample a. The samples for a and b were collected at the interfaces of two liquid phases (see main text). All of the spectra are consistent with $n$-octylamine-ligation.

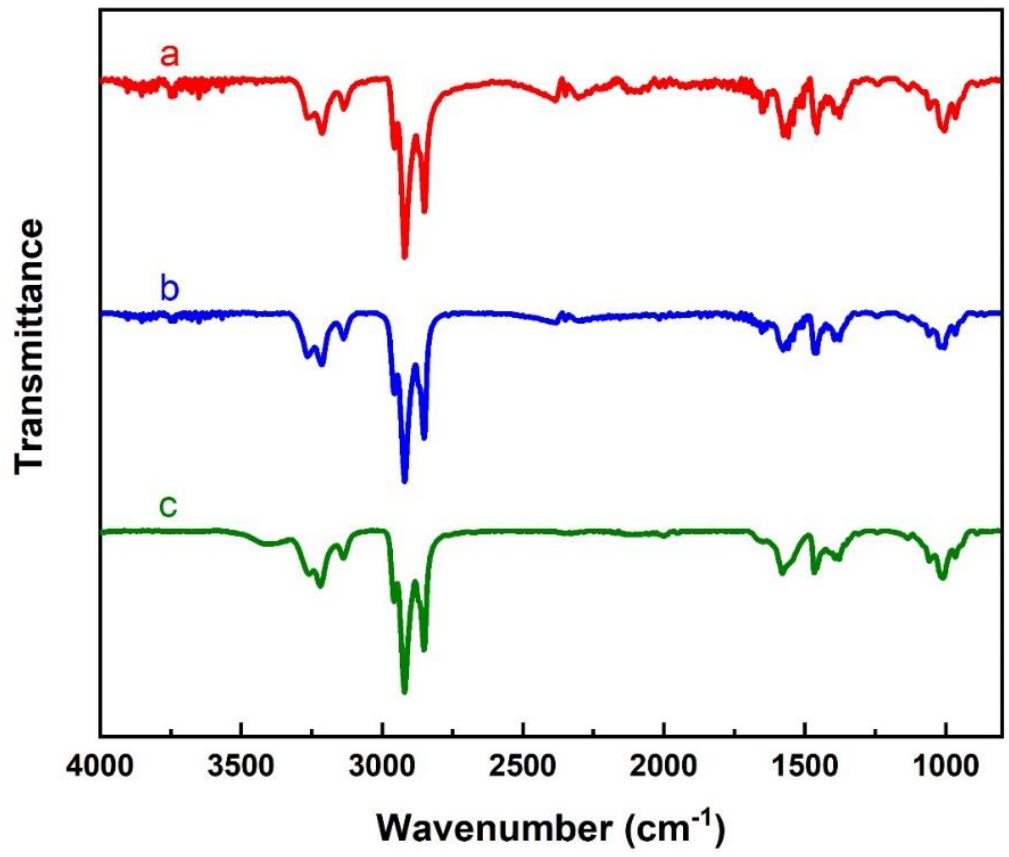

Figure S12. IR spectra after attempted two-phase ligand exchange with (a) $\mathrm{NaCl}$, and (b) $\mathrm{CsBr}$, and (c) after addition of excess $n$-octylamine to sample a. The samples for a and b were collected at the interfaces of two liquid phases (see main text). All of the spectra are consistent with $n$-octylamine-ligation. 
Table S2 Spectral Data for the Lowest-Energy Absorptions of [NH4]X-Ligated CdSe NPLs Obtained from Ligand Exchanges Conducted in Single-Phase Conditions.

\begin{tabular}{cc}
\hline $\begin{array}{c}\text { Ligand-exchange } \\
\text { reagent }\end{array}$ & $\boldsymbol{\lambda}$ max (nm) \\
\hline $\mathrm{NH}_{4} \mathrm{Cl}$ & $467 \pm 1$ \\
$\mathrm{NH}_{4} \mathrm{Br}$ & $466 \pm 1$ \\
$\mathrm{NH}_{4} \mathrm{I}$ & $467 \pm 1$ \\
\hline
\end{tabular}




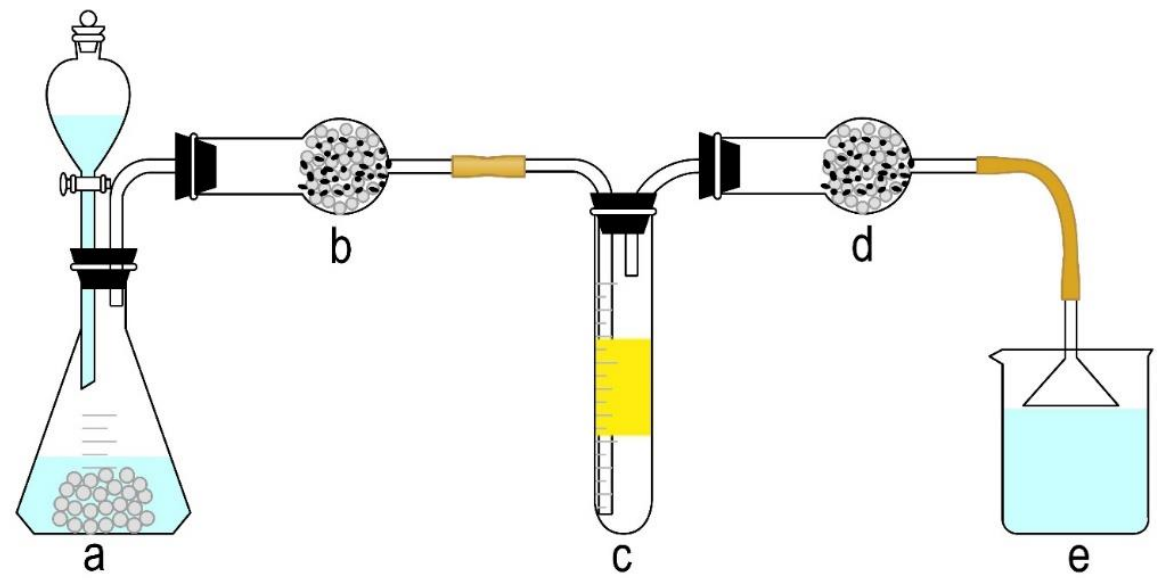

Figure S13. Apparatus for conducting ligand exchange with gaseous $\mathrm{NH}_{3}$. (a) $\mathrm{NH}_{3}(\mathrm{~g}$ ) generator in which $\left[\mathrm{NH}_{4}\right] \mathrm{OH}(\mathrm{aq})$ is added dropwise to $\mathrm{NaOH}$ pellets, forming gaseous $\mathrm{NH}_{3}$; (b) drying tube containing $\mathrm{CaO}$ and $\mathrm{NaOH}$; (c) reaction tube for two-phase ligand exchange; (d) drying tube containing $\mathrm{CaO}$ and $\mathrm{NaOH}$; (e) inverted funnel in water to trap the excess $\mathrm{NH}_{3}(\mathrm{~g})$. 